\title{
SUBJETIVIDADE E LINGUAGEM NA OBRA DE MERLEAU-PONTY
}

\author{
Rafael Ramos Gonçalves
}

Resumo: A linguagem, produto da atividade social dos seres humanos, é assumida pela Psicologia como um elemento importante no estudo da subjetividade. $O$ presente artigo propõe investigar a importância deste tema a partir da obra do filósofo francês Maurice Merleau-Ponty. $O$ texto encontra-se dividido em duas partes: na primeira são apresentadas reflexões sobre a potência expressiva do corpo e sua importância para a dissolução da oposição entre res cogitans e res extensa nas considerações sobre a constituição do sentido das palavras. Na segunda parte aborda-se a relação entre a fenomenologia da linguagem e a expressividade do corpo, permitindo compreender por que as relações entre subjetividade e linguagem estão radicadas na estrutura do ser-no-mundo.

Palavras-chave: Fenomenologia.Corpo. Subjetividade. Linguagem.

Em 1946, no debate que sucedeu sua palestra na Sociedade Francesa de Filosofia, Merleau-Ponty foi indagado por Bréhier sobre seu esforço de retornar "às

1 Este artigo é parte da dissertação de Mestrado defendida no Programa de Pós-graduação em Psicologia Social da UERJ, intitulada "A expressão da subjetividade na filosofia de Merleau-Ponty". A pesquisa contou com o auxílio financeiro da CAPES. 
coisas mesmas" mediante o estudo da percepção. Segundo Bréhier, a formulação de tal projeto abrigaria uma contradição, pois o ato de descrever, característica do método fenomenológico escolhido para desenvolver seu trabalho, já seria um afastamento do vivido imediato, proposto como o principal objeto da investigação merleaupontiana. Diante deste questionamento, Merleau-Ponty (1990) deu a seguinte resposta, bastante sugestiva a respeito do tema deste artigo:"Acreditava ter indicado de passagem que a descrição não é um retorno ao imediato... O que nos encoraja é que não há vida pura e absolutamente inexpressa no homem, e que o irrefletido só começa a existir para nós através da reflexão" (pp. 71-72). Esse fragmento mostra que seu projeto filosófico pretendia um retorno à expressão do vivido, sim, mas apoiado na tese de que a expressão é inseparável do expresso, de modo que o ato de expressar o vivido é o único modo de manifestá-lo. Portanto, a formulação de seu projeto é possível porque não existe o imediato puro, pois as coisas e os sujeitos participam de uma expressividade comum presente no ato perceptivo.

A eleição do método descritivo no estudo da percepção tinha por objetivo evitar a influência dos pressupostos existentes sobre ela, os quais deveriam ser colocados "entre parênteses", para favorecer o retorno à experiência da percepção em sua dimensão originária. $O$ método descritivo, característico das investigações fenomenológicas, consiste no emprego das palavras para atingir o que elas mesmas não conseguem captar por completo:"a saber, a ocorrência inaugural e inalienável do mundo da percepção" (Müller, 2001, p. 134).

Essas indicações revelam que a linguagem é, de certo modo, um tema subjacente à Fenomenologia da Percepção. Dada a importância do método descritivo na condução de suas investigações, bem como o pressuposto de que nada há de inexpresso na vida humana, é preciso considerar a necessidade experimentada por Merleau-Ponty de abordar o fenômeno da linguagem, a fim de compreender de que modo uma descrição poderia ser realizada livre de pressupostos. Em resumo: é preciso indicar"o ponto de tangência entre linguagem e a experiência perceptiva, de modo a justificar sua empresa filosófica" (Müller, 2001, p. 134).

A crítica que inaugura o desenvolvimento desse percurso dirige-se à concepção de que a linguagem serve para traduzir pensamentos, os quais estariam localizados numa região isolada da experiência. Se a linguagem for tomada como invólucro de pensamentos gerados no "mundo das ideias", parece inviável o seu emprego na transmissão da experiência perceptiva, a qual pertencente à ordem de fenômenos do tipo res extensa e, portanto, inconciliável com as produções mentais, do tipo res cogitans.

Merleau-Ponty contesta, a partir da fenomenologia do corpo, tal oposição entre as duas ordens de fenômeno; é a partir da corporeidade 
que ele edifica sua análise sobre a linguagem, defendendo que a produção de significados nos usos linguísticos não se relaciona às experiências do corpo como algo à parte, do mesmo modo que não há exterioridade entre linguagem e pensamento, mas relação de mútua implicação: o sentido já está embutido na fala e esta é a própria manifestação do sentido:

Por que seria mais fácil lembrar-se das palavras ou das frases do que lembrarse dos pensamentos, se a cada vez as pretensas imagens verbais precisam ser reconstruídas? E por que o pensamento procuraria duplicar-se ou revestir-se de uma série de vociferações se elas não trouxessem e não contivessem em si mesmas seu sentido? (Merleau-Ponty, 1999, p. 247)

Nota-se, nesse fragmento, que as palavras, supostamente exteriores, são introduzidas no pensamento, assinalando até mesmo uma dependência deste em relação àquelas "vociferações". A noção de fala $\mathrm{fa}^{2}$ lante, que, segundo Müller (2001), Merleau-Ponty desenvolve para tentar demonstrar a possibilidade de descrição da experiência perceptiva, está intimamente relacionada ao plano da corporeidade e suas implicações no que diz respeito à superação da dicotomia entre res cogitans e res extensa.

A designação fala falante refere-se ao ato de fala que inaugura uma significação. Nessa modalidade, a existência assume um sentido "em suspenso", pois é "para além do ser que ela procura alcançar-se e é por isso que ela cria a fala como apoio empírico de seu próprio não-ser. A fala é o excesso de nossa existência por sobre o ser natural" (Merleau-Ponty, 1999, p. 267). Contudo, esse mesmo ato de expressão, que ultrapassa a existência imediata rumo a um sentido novo, constitui um "mundo linguístico e cultural, ele faz voltar a cair no ser aquilo que tendia para além" (p.267). A fala falante é um artifício que permite apresentar a possibilidade de descrever o mundo da percepção sem empregar pensamentos constituídos, pois esta modalidade de fala é inaugural, ou seja, é a partir dela que novos pensamentos são elaborados. Ela não dispensa por completo o que está constituído, mas utiliza-se do que está estabelecido para lançar-se além, instaurando novas significações.

Apesar desta tentativa, Müller (2001) avalia que a noção de fala falante é insuficiente para demonstrar que a descrição é suficiente para manifestar o mundo da percepção; é indispensável que se responda à seguinte questão: de que modo a fala falante pode exprimir o que não

20 termo fala não se aplica apenas à vociferação. De acordo com Moutinho (2006), esse termo "parece incluir antes toda operação expressiva que se serve da língua" (p. 307). 
pertence ao âmbito do pensamento, neste caso, a percepção? ${ }^{3}$ Para responder a tal pergunta é necessário abordar o caráter existencial da expressão.

\section{A expressividade do corpo}

Segundo Müller (2001), expressão é um conceito que na obra de Merleau-Ponty designa a "relação de fundação ${ }^{4}$ ou não independência entre o que eu trago de espontâneo - minha vida junto ao mundo da percepção - e aquilo que eu trago de constituído - minhas palavras, as significações linguageiras e conceituais" (Müller, 2001, p. 155). Por isso considera-se que a fala falante não suscita, simplesmente, novos pensamentos, como se estes surgissem do nada, mas promove arranjos linguísticos que realizam um estilo já atuante em outras falas ou ações do sujeito. Tal fala permite que o modo de existir do falante seja revelado, isto é, "o modo como ele está inserido no mundo da percepção" (p. 143). Nesse sentido, a descrição do mundo da percepção mostra-se viável em virtude da dimensão existencial da linguagem, pois falar é "executar a mímica de nossas dimensões físicas, práticas e afetivas" (p. 147) que não são contidas totalmente nas palavras, mas que são indissociáveis do próprio ato da fala.

O ritmo da fala ou a ênfase em determinadas palavras são mais do que uma ocorrência linguística banal, pois expressam a "intenção vital da qual o falante está investido: pressa, descaso, medo, ansiedade, desejo" (Müller, 2001, p. 146). A subjetividade insinua-se na linguagem porque ambas vinculam-se à corporeidade, de modo que as palavras funcionam como mímica das experiências realizadas no mundo da percepção. É a significação existencial, captada na percepção, que torna possível a presença de significação nas formas linguísticas. As imagens, sons e gestos não verbais empregados num diálogo, por exemplo, não são apenas elementos discursivos, mas também executam uma certa disposição corpo-

3 Essa interrogação é importante porque introduz a crítica à dicotomia entre sujeito e objeto a partir da relação entre a experiência corporal e sua expressão subjetiva. De que modo o percebido pode se tornar expresso se a fala e os pensamentos não pertencem ao mundo da percepção? Ou ainda: como se estabelece tal comunicação entre o percebido e o subjetivo?

40 termo fundação (Fundierung) é característico da filosofia fenomenológica. Merleau-Ponty (1999) explica que esse termo refere-se a uma relação de dupla direção, que supera a tradicional concepção de tempo linear, composta de relações causais. Nesse sentido, o termo fundante é primeiro porque o"fundado se apresenta como uma determinação ou uma explicitação do fundante, o que lhe proíbe de algum dia reabsorvê-lo, e todavia o fundante não é primeiro no sentido empirista e o fundado não é simplesmente derivado dele, já que é através do fundado que o fundante se manifesta" (p. 527). A dimensão de equívoco é assumida como definitiva em sua filosofia. 
ral, revelando "as inclinações e idiossincrasias, as limitações e comprometimentos de nossa existência junto a um contexto físico, pragmático e afetivo, mesmo que não tivéssemos desejado isso" (p. 146).

A transmissão da significação pela fala é análoga à da expressão gestual. Não se percebe, por exemplo, a raiva como algo separado do gesto, tal como entendiam os intelectualistas e empiristas com relação à palavra. De acordo com Merleau-Ponty (1999), "eu leio a cólera no gesto, o gesto não me faz pensar na cólera, ele é a própria cólera" (p. 251). O gesto já é em si mesmo uma reflexão, ele já é sentido anterior à consciência, embora seja impossível perceber, no gesto, a cólera tal como é vivida pelo sujeito.

Ele entende que não há oposição entre o que é natural, como as reações emotivas e seus componentes fisiológicos, e o que é supostamente artificial, como os signos utilizados para exprimir tais reações. Assim como no plano da linguagem, as manifestações corporais são contingentes, ou seja, o fato de possuirmos estruturas corporais semelhantes não implica em ações programadas, idênticas para todos. Nessa passagem de suas considerações, Merleau-Ponty volta-se para a dimensão cultural para ilustrar a contingência do ser-no-mundo e sua relação com o gesto corporal:

a mímica da cólera ou a do amor não são as mesmas para um japonês e para um ocidental. Mais precisamente, a diferença das mímicas esconde uma diferença das próprias emoções. Não é apenas o gesto que é contingente em relação à organização corporal, é a própria maneira de acolher a situação e de vivê-la. O japonês encolerizado sorri, o ocidental enrubesce e bate o pé, ou então empalidece e fala com uma voz sibilante. (Merleau-Ponty, 1999, p. 256)

Em seguida ele nos conduz ao cerne da relação cultura-comportamento, situando no corpo a origem das divergências entre os significados gestuais de diferentes grupos:

Não basta que dois sujeitos conscientes tenham os mesmos órgãos e o mesmo sistema nervoso para que em ambos as mesmas emoções se representem pelos mesmos signos. O que importa é a maneira pela qual eles fazem uso do seu corpo, é a enformação de seu corpo e de seu mundo na emoção. (MerleauPonty, 1999, pp. 256-257)

Uma palavra só pode manifestar algum sentido enquanto parte da situação do sujeito, e por esse motivo a mera escuta dos sons das palavras não garante a compreensão do que é dito. Uma criança terá dificuldades no entendimento das falas que lhe são dirigidas se o código linguístico de sua cultura não tiver sido introduzido em sua existência particular. Assim, o aprendizado de uma nova palavra não pode ser redu- 
zido à aquisição de uma nova representação ou mero conhecimento objetivo, pois

ela é um certo uso do meu aparelho de fonação, uma certa modulação de meu corpo enquanto ser no mundo, sua generalidade não é a generalidade da ideia, mas a de um estilo de conduta que meu corpo "compreende" enquanto ele é uma potência de fabricar comportamentos e em particular fonemas. (Merleau-Ponty, 1999, p. 540)

A palavra é assumida como possibilidade da potência motora, isto é, manifestação da experiência do corpo e de seus campos perceptivos. Quanto ao sentido da palavra, ele é apreendido do mesmo modo que se apreende o uso de um utensílio, ou seja,"vendo-o empregado no contexto de uma certa situação" (Merleau-Ponty, 1999, p. 540). O sentido conferido a um termo da língua está em estreita dependência da experiência do sujeito, a qual lhe dá certa fisionomia.

Essas considerações ajudam a compreender por que Merleau-Ponty (1999), ao abordar a perspectiva empirista e intelectualista sobre a linguagem, ressalta que ambas desconsideram o caráter expressivo da palavra. Segundo ele, a palavra não é invólucro para a ideia produzida pelo pensamento (intelectualismo) nem a resultante de eventos mecânicos, exclusivamente objetivos, sem espaço para qualquer tipo de participação da ordem subjetiva (empirismo).

Para analisar a manifestação do sentido em uma palavra faz-se necessário retornar ao lugar de onde ela emana enquanto movimento expressivo. No caso da filosofia de Merleau-Ponty (1999), o destaque é dado à importância da percepção como ato cuja estrutura é significação, onde se estabelece a abertura de mundo através da qual a linguagem prossegue, na "medida em que retoma, transforma e prolonga as relações de sentido iniciadas na percepção" (Furlan \& Bocchi, 2003, p. 446).

O emprego conjugado dos termos gesto e expressão em diversos momentos da obra merleaupontiana tem por objetivo ressaltar que a manifestação do sentido não é obra de uma consciência que paira sobre a realidade, mas é gesto e, sendo assim, possui caráter existencial. Isso significa que os significados partilhados dependem da corporeidade, cuja análise fenomenológica revela a subjetividade enredada no mundo. Consequentemente, a linguagem não pode expressar o pensamento enquanto realidade separada da existência; ao contrário, "ela é tomada de posição do sujeito no mundo de suas significações" (MerleauPonty, 1999, p. 262). Esse mundo, explica o filósofo, refere-se ao fato de que os aspectos relacionados à vida mental ou cultural estão fundados nas estruturas naturais, isto é, no "sujeito encarnado", mas não se reduzem a elas: 
O gesto fonético realiza, para o sujeito falante e para aqueles que o escutam, uma certa estrutura da experiência, uma certa modulação da existência, exatamente como um comportamento de meu corpo investe os objetos que me circundam, para mim e para o outro, de uma certa significação.(Merleau-Ponty, 1999, p. 262)

Em função do corpo-próprio, que não se deixa capturar simplesmente em seus processos fisioanatômicos, pode-se compreender o caráter inesgotável da expressão.É o ato expressivo que constitui um mundo linguístico e cultural, em que se retém no ser o que "tendia para além" (Merleau-Ponty, 1999, p. 267).É esse movimento de tender para além, característico da expressão, que o filósofo detecta na linguagem, a qual "se reitera, apoia-se em si mesma ou que, assim como uma onda, ajunta-se e retoma-se para projetar-se para além de si mesma" (p. 267).

\section{Subjetividade e linguagem}

Em sua abordagem fenomenológica da linguagem, o filósofo defende que ela se efetiva em relação a um "sujeito falante que usa sua língua como meio de comunicação com uma comunidade viva" (MerleauPonty, 1980c, p. 130). Essa declaração revela o esforço de Merleau-Ponty para afastar-se da concepção de que a linguagem seria apenas uma resultante do acúmulo de significações produzidas ao longo da história, e que esta seria a dimensão privilegiada nas trocas simbólicas, sendo irrelevante a participação do sujeito na atualização das significações.

Ele vai se contrapor a esse pensamento ao propor a necessidade de retornar ao ato da fala para que a fecundidade e peculiaridade do fenômeno da expressão sejam devidamente captadas. Assim, pretendo mostrar que ele reflete sobre a língua não mais como produto acabado de eventos passados determinando os sujeitos, mas como"sistema cujos elementos concorrem para um esforço único de expressão" (Merleau-Ponty, 1980c, p. 130) que jamais é concluído, e do qual todos participamos. Desse modo, a língua materna, e também os demais patrimônios culturais herdados, são inseparáveis do presente, não havendo cisão entre a linguagem usada na redação deste artigo, por exemplo, e a herança linguística que me precede. Afinal, o "subjetivo sempre envolve o objetivo" ( $p$. 131) nesse esforço de ultrapassar a existência imediata.

Parece que Merleau-Ponty estende ao fenômeno da linguagem sua tentativa de afastar a dicotomia entre sujeito e objeto, eu e outro, privado e público, dando destaque à expressividade do mundo vivido, antecipando de certa maneira a formulação sobre a "carne do mundo", termo que em sua última obra é usado para designar o caráter imiscuído da relação entre o corpo e o mundo. As coisas do mundo comparecem, nessa perspectiva, como parte do sujeito, e não como objeto de sua consciência. 
Essa concepção também permite entender por que, quando se fala, é desnecessário efetuar operações mentais destinadas a efetuar o arranjo entre as intenções e os meios de expressão disponíveis. A expressão das intenções emerge a partir da organização espontânea das palavras, associada ao mesmo fenômeno da expressão verificado quando se tratou da relação entre corpo (percepção) e linguagem. Por essa razão, observa Merleau-Ponty,"os signos organizados têm seu sentido imanente, e este não depende do 'eu penso', mas do 'eu posso'" (p. 133), que, agindo no mundo, engendra novas possibilidades expressivas. Se a palavra proferida ou ouvida possui um significado acoplado ao gesto linguístico, isso decorre da expressividade da "carne do mundo", ou seja, da produção do sentido no plano do sensível.

O estudo da linguagem permite apreender um certo avanço no interior da própria obra do filósofo, apreensível no que já havia sido proposto na Fenomenologia da Percepção: a consciência não detém a prerrogativa sobre o sentido alcançado na expressão. Em um momento mais avançado de suas elaborações Merleau-Ponty (1980c) afirma que "para o sujeito falante, exprimir é tomar consciência" (p. 134) e, sendo assim, a consciência, e o próprio pensamento, derivam da expressão. $O$ ato expressivo revela ao próprio sujeito de que maneira ele se situa no mundo de suas significações, instaurando a condição para que ele reflita sobre ela, pois o sujeito falante "não exprime somente para os outros, exprime para que ele próprio saiba o que visa" (p.134). O sujeito só pode conhecer a si mesmo nesta dimensão de alteridade, de onde recolhe os materiais indispensáveis para delinear sua vida.

É interessante perceber o modo como a fenomenologia da linguagem vai contra qualquer tipo de instância do sujeito responsável pela produção do sentido. Suas análises explicitam que a subjetividade não pode ser considerada uma instância isolada que produz sentido porque ela mesma está enfronhada nos interstícios constituídos nas relações entre o corpo e as coisas, sendo impossível discernir um sujeito e um objeto.

Merleau-Ponty defende que é ilusória a expectativa de que nossas expressões possam dizer algo com absoluta precisão, pois a linguagem significa de modo oblíquo, indireto, do mesmo modo que as pegadas indicam o movimento de um corpo, o que inviabiliza a restituição de uma espécie de nexo causal entre a consciência e o sentido que a expressão revela. $O$ aparecimento do sentido na linguagem pode ser compreendido observando o ofício do escritor que,"como o tecelão, trabalha às avessas: preocupa-se unicamente com a linguagem e em sua trilha vê-se de repente rodeado de sentido" (Merleau-Ponty, 1980a, p. 145).

O exemplo da pintura é um dos que, na obra de Merleau-Ponty, indica a subversão da noção cartesiana de sujeito e aponta de outro modo para sua inerência ao mundo. 
A significação colocada na pintura não é decalque do mundo circundante, mesmo que haja o esforço de reproduzir fielmente os aspectos de um objeto ou paisagem. A pintura manifesta um certo modo de nos relacionarmos com o mundo, de tal modo que "o pintor em ação desconhece a antítese do homem e do mundo, da significação e do absurdo" (Merleau-Ponty, 1980a, p. 152). A percepção do pintor modula as impressões do ambiente e, nessa modulação, configura um sistema de equivalências entre os elementos que vão enformar sua expressão. Um transeunte, por exemplo, não é percebido como "contorno corporal, manequim colorido, espetáculo, antes'expressão individual, sentimental, sexual'"' (Merleau-Ponty, 1980a, p. 152) apreendida imediatamente pelo sujeito. O mesmo se verifica na linguagem ouvida ou falada, onde não são captados substantivos, adjetivos ou orações, mas certo modo de gesticulação verbal que veicula a recuperação de experiências de um mundo particular.

Outro exemplo da compreensão de Merleau-Ponty sobre a correlação entre linguagem e subjetividade é o comentário a respeito da influência que o passado de Leonardo da Vinci exerceu em sua pintura. De acordo com o filósofo, se Leonardo foi bem-sucedido em sua trajetória artística, apesar da infância infeliz, isso não significa que ele detenha atributos típicos de um ser sobrenatural, imune, portanto, às contingências da vida. Seu êxito deve ser atribuído ao fato de que ele assumiu suas vivências de modo singular, manifestando um certo modo de estar-nomundo:"sua situação corpórea ou vital foi por ele constituída em linguagem. Passando-se da ordem dos acontecimentos à da expressão, não se muda de mundo: os mesmos dados a que se estava sujeito tornam-se sistema significante" (Merleau-Ponty, 1980a, p. 160). A obra do pintor é a cristalização das vivências pessoais ou dos eventos históricos, impulsionada por um motivo, de modo que a pintura não é resultado das condições sócio-históricas, mas resposta a elas. A espontaneidade das palavras ou dos traços na tela, assim como os gestos do corpo, explica "quem somos por nossas raízes, nosso impulso e, como se diz, pelos frutos do nosso labor" (Merleau-Ponty, 1980a, p. 169).

A situação em que o sujeito está inserido é o que importa na expressão subjetiva. Sem a referência a essa dimensão a linguagem serviria apenas para transmitir a coisa em si mesma, reabilitando o sujeito atemporal que toda a filosofia de Merleau-Ponty procura contestar:

O que queremos dizer não se mostra, fora de toda palavra, como pura significação. Não é senão o excesso do que vivemos sobre o que já foi dito. Encontramo-nos com nossos recursos de expressão numa situação à qual é sensível, confrontamo-lo a ela e nossos dizeres não são senão o balanço final desse intercâmbio. (Merleau-Ponty, 1980a, p. 175) 
Se nem o amor pode acontecer apenas por princípios, dissociado da ação que o verbo amar designa, é impossível até mesmo formular ideais políticos prescindindo do mundo. $O$ conceito, as ideias e os planos brotam da experiência, são elaborações da percepção, onde está envolvida a subjetividade, com seus conhecimentos e valores, enfim, com suas linguagens.

\section{Considerações finais}

O desenvolvimento do pensamento de Merleau-Ponty parecia orientar-se inevitavelmente à radicalização da pertença ao mundo apreendida inicialmente na fenomenologia da percepção. A ultrapassagem de si mesmo nas reflexões contidas em $O$ visível e o invisível correspondeu à conclusão de um movimento de superação do Cogito cartesiano cujos rudimentos já se mostravam na Fenomenologia da Percepção. Merleau-Ponty mostra que a linguagem é movimento da existência, em que percepção e subjetividade se alternam indefinidamente, sem jamais alcançar uma síntese definitiva. A subjetividade situa-se nesse movimento de reversibilidade, onde eu e outro são apenas momentos do ser-nomundo. Especialmente o fenômeno da percepção de outrem, devidamente trabalhada na Fenomenologia da Percepção, demonstra que "o mundo comum é aqui o mundo do qual os sujeitos são coextensivos: não é apenas um mundo de coisas naturais, mas também de sujeitos (e objetos)" (Moutinho, 2006, p. 217).

Em uma nota de trabalho de 1960, dedicada à noção de quiasma, pode-se comprovar a superação do Cogito cartesiano comentada anteriormente. Merleau-Ponty parece ter alcançado uma concepção que responde satisfatoriamente aos seus questionamentos sobre a relação entre o sujeito e o mundo, para além da alternativa Para-Si/Para-Outro:

Reversibilidade: o dedo da luva que se põe do avesso - Não há necessidade de um espectador que esteja dos dois lados. Basta que, de um lado, eu veja o avesso da luva que se aplica sobre o direito, que eu toque um por meio do outro... o quiasma é isto: a reversibilidade.É somente através dela que há passagem do Para Si ao Para Outrem. Na realidade, não existimos nem eu nem o outro como positivos, subjetividades positivas. São dois antros, duas aberturas, dois palcos onde algo vai acontecer...e ambos pertencem ao mesmo mundo. Não existe o Para-Si e o Para Outrem. Eles são o outro lado um do outro. (Merleau-Ponty, 1971, p. 237)

Em outra nota de trabalho de O Visível e Invisível, escrita em julho de 1959, ele admite que"os problemas colocados na [Fenomenologia da Percepção] são insolúveis" porque ele desenvolve suas reflexões apoiado na "distinção 'consciência' - 'objeto'" (Merleau-Ponty, 1971, p. 189). 
Müller (2001), ao abordar essa questão, comenta que a terminologia de Merleau-Ponty ainda estava impregnada pelas distinções ontológicas que sustentam as teorias da representação presentes no empirismo e intelectualismo, tomados como objeto de sua crítica em alguns momentos da obra. Embora a análise da corporeidade desfaça a dicotomia entre o sujeito e o mundo, nota-se, segundo ele, que ainda permanece um certo privilégio a um dos termos da relação.

Merleau-Ponty considerou, de fato, a subjetividade como um dos polos da experiência, estabelecendo o mundo como outro. Porém, eles não são isolados, mas estão articulados no corpo, pois somente a partir da percepção é possível obter algum contato consigo mesmo. Daí porque ele remete, por exemplo, a linguagem à percepção, afirmando que só podemos apreender a nós mesmos enquanto falantes apoiados neste Cogito tácito, formado na implicação entre corpo e mundo.

Merleau-Ponty, em determinado momento de sua obra, propõe um Cogito que, sendo tácito,"não está mediado por representações e, nesse sentido, não pode resumir ou antecipar nada" (Müller, 2001, p. 214). O próprio Merleau-Ponty admitirá, no entanto, que uma tal consciência de si só é possível mediante a linguagem: “O que chamo de cogito tácito é impossível... para retornar à imanência e à consciência de...é preciso possuir as palavras" (Merleau-Ponty, 1971, p. 168).

Em muitos momentos de sua argumentação, Merleau-Ponty trabaIha com pressupostos idealistas relativos à linguagem para refutá-los. $O$ que ele contesta no idealismo é esta pretensão de redução subjetiva, eliminada qualquer possibilidade de equívoco entre sujeito e objeto. Ora, suas observações acerca da linguagem serviram para mostrar que as significações não são positivas, e que existe uma opacidade nas intenções de significar. Não há identidade entre sujeito e o objeto da expressão, o que se confirma pelo fato de que a linguagem sempre dá mais do que nela pretendemos introduzir.

Merleau-Ponty elabora uma gênese da linguagem a partir do corpo. Isso não corresponde à tentativa de apresentar uma nova forma de realizar as operações de síntese ou associação atribuídas à concepção cartesiana de subjetividade, mas objetiva tão somente mostrar que no corpo "os dados mundanos e os nossos dispositivos convergem como síntese inacabada" (Müller, 2001, p. 316), atualizada pelo uso da linguagem. 


\title{
Subjectivity and language in Merleau-Ponty
}

\begin{abstract}
Language, the result of social practice among human beings, is regarded by Psychology as a major element in the study of subjectivity. This article aims at arguing the relevance of this theme on the basis of the work of French philosopher Maurice Merleau-Ponty. The text is divided into two parts. The first one includes reflections on the body's expressive potency and its relevance to the dissolution of the opposition between res cogitans and res extensa as for the constitution of meaning to words. The second one investigates the relation between phenomenology of language and body expressivity, allowing for understanding why subjectivity and language are rooted in the structure of the being-in-the-world.
\end{abstract}

Keywords: Phenomenology. Body. Subjectivity. Language.

\section{Subjectivité et langage dans l'œuvre de Merleau-Ponty}

Résumé: Produit de l'activité sociale des êtres humains, le langage est considéré par la Psychologie comme un élément important dans l'étude de la subjectivité.Cet article analyse l'importance de tel sujet a partir de l'œuvre du philosophe français Maurice Merleau-Ponty. Le texte est partagé en deux parties : dans la première, on presente des refletions sur la puissance expressive du corps et son importance pour la dissolution de l'opposition entre res cogitans et res extensa dans les considérations sur la constitution du sens des mots. Dans la deuxième partie, on approche le rapport entre la phénoménologie du langage et l'expressivité du corps, ce qui permet de comprendre pourquoi les rapports entre subjectivité et langage sont à la racine de la structure de l'être-dans-le-monde.

Mots-clés: Phénoménologie. Corps. Subjectivité. Langage.

\section{Subjetividad y lenguaje en la obra de Merleau-Ponty}

Resumen: El lenguaje, producto de la actividad social de los seres humanos, es asumido por la Psicología como un elemento importante en el estudio de la subjetividad. El presente artículo propone investigar la importancia de este tema a partir de la obra del filósofo francés Maurice Merleau-Ponty. El texto se encuentra dividido en dos partes: en la primera son presentadas reflexiones sobre la potencia 
expresiva del cuerpo e su importancia para la disolución de la oposición entre res cogitans e res extensa en las consideraciones sobre la constitución del sentido de las palabras. En la segunda parte se aborda la relación entre la fenomenología del lenguaje e la expresividad del cuerpo, permitiendo comprender por que las relaciones entre subjetividad y lenguaje están radicadas en la estructura del ser-en-elmundo.

Palabras clave: Fenomenología. Cuerpo. Subjetividad.Lenguaje.

\section{Referências}

Furlan, R. F., \& Bocchi, J. C. (2003). O corpo como expressão e linguagem em Merleau-Ponty. Estudos de Psicologia, 8(3), 445-450. Recuperado em 23 de janeiro de 2006, de www.scielo.br/pdf/epsic/v8n3/19966.pdf

Merleau-Ponty, M.(1980a). A linguagem indireta e as vozes do silêncio.In M.Chauí (Org.), Merleau-Ponty (pp. 141-175). São Paulo: Abril Cultural.

Merleau-Ponty, M.(1980b).Em toda e nenhuma parte.In M.Chauí (Org.),MerleauPonty (pp. 209-237). São Paulo: Abril Cultural.

Merleau-Ponty, M. (1980c). Sobre a fenomenologia da linguagem. In M. Chauí. (Org.), Merleau-Ponty (pp. 129-140). São Paulo: Abril Cultural.

Merleau-Ponty, M. (1990). O primado da percepção e suas conseqüências filosóficas. Campinas, SP: Papirus.

Merleau-Ponty, M. (1999). Fenomenologia da percepção. São Paulo: Martins Fontes.

Müller, M. (2001). Merleau-Ponty acerca da expressão. Porto Alegre: EDIPUCRS.

Moutinho, L. D. (2006). Razão e experiência: ensaios sobre Merleau-Ponty. Rio de Janeiro: Ed. da UNESP. 
Rafael Ramos Gonçalves, Mestre em Psicologia Social pela Universidade Estadual do Rio de Janeiro.Endereço para correspondência: Av.Santa Cruz, 6496 Apto. 104,Bangu, Rio de Janeiro, RJ, Brasil.CEP:21830-009. Endereço eletrônico: rafrj@yahoo.com.br.

Recebido: 08/09/2009

Aceito: $22 / 11 / 2010$ 